\title{
Impact of short-term exposure to extreme temperatures on diabetes mellitus morbidity and mortality? A systematic review and meta-analysis
}

\author{
Xuping Song \\ School of Public Health, Lanzhou University, Lanzhou 730000, China \\ Liangzhen Jiang \\ School of Public Health, Lanzhou University, Lanzhou 730000, China, \\ Dongdong Zhang \\ School of Public Health, Lanzhou University, Lanzhou 730000, China \\ Xinyi Wang \\ Second Clinical College, Lanzhou University, Lanzhou 730000, China \\ Yan Ma \\ School of Public Health, Lanzhou University, Lanzhou 730000, China \\ Yue Hu \\ School of Public Health, Lanzhou University, Lanzhou 730000, China \\ Jing Tang \\ School of Public Health, Lanzhou University, Lanzhou 730000, China

\section{Xiayang Li} \\ School of Public Health, Lanzhou University, Lanzhou 730000, China

\section{Wenqiang Huang} \\ School of Pharmacy, Lanzhou University, Lanzhou 730000, China
}

\section{Yuan Meng}

Laboratory of Cancer Biology, Key Lab of Biotherapy in Zhejiang, Sir Run Run Shaw Hospital, Medical School of Zhejiang University, Hangzhou 310000, China

\section{Anchen Shi}

Department of General Surgery, The First Affiliated Hospital of Xi'an Jiao Tong University, Shaanxi 710061, China

Yan Feng

School of Public Health, Lanzhou University, Lanzhou 730000, China

Yan Zhang ( $\sim$ Zhangyan20210103@126.com)

Gansu Province Hospital Rehabilitation Center

\section{Research Article}

Keywords: Extreme temperature, Heat, Cold, Diabetes, Systematic review, Meta-analysis.

Posted Date: March 19th, 2021

DOI: https://doi.org/10.21203/rs.3.rs-320376/v1

License: () (i) This work is licensed under a Creative Commons Attribution 4.0 International License. Read Full License 


\section{Abstract}

The relationship between diabetes mellitus and short-term exposure to extreme temperatures remains controversial. A systematic review and metaanalysis were performed to assess the association between extreme temperatures and diabetes mellitus morbidity and mortality. PubMed, Embase, the Cochrane Library, Web of Science and the Cumulative Index to Nursing and Allied Health Literature (CINAHL) were searched since inception to January 1 , 2019 , and updated on November 17, 2020. The results were combined using random effects model and reported as relative risk (RR) with $95 \%$ confidence interval (Cl). 32 studies met the included criteria. (1) Both heat and cold exposures have impact on diabetes. (2) For heat exposure, the subgroup analysis revealed that the effect on diabetes mortality $(\mathrm{RR}=1.139,95 \% \mathrm{Cl}: 1.089-1.192)$ was higher than morbidity $(\mathrm{RR}=1.012,95 \% \mathrm{Cl}$ : $1.004-1.019)$. $(3)$ With the increase of definition threshold, the impact of heat exposure on diabetes rised. (4) A stronger association between heat exposure and diabetes was observed in the elderly ( $\geq 60$ years old) $(\mathrm{RR}=1.040,95 \% \mathrm{Cl}$ : 1.017-1.064). In conclusion, both short-term exposure to heat and cold temperatures have impact on diabetes. The elderly is the vulnerable population of diabetes exposure to heat temperature. Developing definitions of heatwaves at the regional level are suggested.

\section{Background}

The Intergovernmental Panel on Climate Change indicated that the impact of climate change on public health attracted extensive attention in $21 \mathrm{st}$ century (Allen et al. 2014). Climate change is already causing tens of thousands of deaths every year and has attracted more and more attention (World Health Organization 2016a). There is a great threat that global climate change will increase in the future (Hansen et al. 2012). Extreme temperatures, such as heat effect and cold effect, is an important respect of climate change and a significant risk factor for human health throughout the world, associations of temperatures with morbidity and mortality have been supported in numerous scientific literatures (Bayram 2017 and Gronlund et al. 2018). In China, a country with one-fifth of the world's population, the number of deaths related to heat-waves increased four-fold from 1990 to 2019 , reaching 26,800 in 2019 (Cai et al. 2020).

Diabetes mellitus is a serious, chronic metabolic disease and important public health problem. Diabetes could lead to numerous health problems, without reasonable control (World Health Organization 2016b), such as serious damage to heart, blood vessels, eyes, kidneys, and nerve. There is well-evidenced that the increase of diabetes, evidence indicated that the world prevalence of diabetes was estimated to increase $1.3 \%$ from 2010 to 2030 . Global report on diabetes indicated that in 2012 alone diabetes led to 1.5 million deaths, the number of adults living with diabetes has almost quadrupled since 1980 to 422 million adults (World Health Organization 2016b). The burden of diabetes is not only related to the matter of therapy aimed at glycemic control, but also significantly influences the patient's survival, quality of life, and development of organ system degeneration.

A series of systematic reviews have been conducted to estimate the effects of extreme temperature on cardiovascular and respiratory diseases (Bhaskaran et al. 2009; Carolan-Olah and Frankowska 2014; Costello et al. 2009). Though a series of published studies had viewed the relationship of extreme temperatures and diabetes, but the results were inconsistent. No convincing evidence exists that systematically evaluate the associations between extreme temperatures and of diabetes. The aim of this study was to evaluate the impact of heat exposures, cold exposures, heatwaves and cold spells on diabetes morbidity and mortality, and identify the vulnerable population affected by extreme temperatures.

\section{Methods}

The protocol of this systematic review was published online at the PROSPERO (registration number: CRD42019132296).

\subsection{Search strategy}

We conducted a systematic search in PubMed, Embase, the Cochrane Library, Web of Science and the Cumulative Index to Nursing and Allied Health Literature (CINAHL) since inception to January 1, 2019, and updated to November 17, 2020. The following U.S. National Library of Medicine's Medical Subject Headings (MeSH) terms and key words were used in search:(climate change* OR temperature*) AND (diabet* OR insulin*) AND (time series OR case crossover). The complete search strategy was shown in Appendix S1.

\subsection{Inclusion and exclusion criteria}

The criteria for eligibility were used: (i) studies that evaluated the effect of extreme temperatures on diabetes morbidity or mortality (ICD-9:250 or ICD10:E10-E14), and (ii) studies design were time series or case crossover; (iii) Extreme temperatures accord with at least one of the following four temperature exposures: cold, heat, cold spells and heat waves; (iv) studies provided at least one of the following estimates: percentage change, relative risk (RR) or odds ratio (OR) with $95 \%$ confidence interval (Cl) or enough information for calculation; and (v) the publication language was restricted to English. The criteria for exclusion were used: (i) studies that evaluated indoor, body, workplace or focused on seasonality temperatures as exposure variables; (ii) studies only providing qualitative evaluation; and (iii) conference abstracts. The definition of temperature exposure was:

Heat exposures:

Definition 1: effect estimates per unit/other increment increase above threshold or no threshold for linear effects;

Definition 2: comparison between heat threshold with the reference value (e.g. 99th vs. 75th percentiles); 
Definition 3: Temperatures above the heat threshold compared with temperatures below the threshold (e.g. above 95th vs. below 95th percentiles);

Cold exposures:

Definition 1: effect estimates per unit/other increment increase below threshold or no threshold for linear effects;

Definition 2: comparison between cold threshold with the reference value (e.g. 1st vs. 25th percentiles);

Definition 3: Temperatures below the cold threshold compared with temperatures above the threshold (e.g. below 25th vs. above 25th percentiles);

Heat waves: temperatures above heat threshold and lasting for 2 or more days.

Cold spells: temperatures below cold threshold and lasting for 2 or more days.

\subsection{Study selection and data extraction}

The screening of potentially eligible studies was carried out using a two-step process. First, four investigators independently screened the potentially eligible studies underwent titles and abstracts. Second, all relevance studies (the screened result by underwent their titles and abstracts) got through fulltext screening on the basis of inclusion and exclusion criteria. Two reviewers independently extracted the relevant data from the included studies. The extracted data from included studies comprise but was not limited to the following items: author, year of publication, study design, temperature exposure type and definition, outcome and statistical methods. Disagreement was resolved by consensus and the opinion of a third reviewer.

\subsection{Data synthesis}

We summarized the characteristics and determined the number of assessing heat exposures, heat waves, cold exposures, and cold spells in all included studies. Temperature indicators of the included studies comprise air temperature (express as ${ }^{\circ} \mathrm{C}$ ), apparent temperature and humidex. Air temperature was considered in the meta-analysis due to the majority of included studies used the indicator.

We conducted the qualitative and quantitative analysis. Meta-analysis was performed to integrate the overall risk on diabetes. For studies with multiple temperature thresholds reported, the maximum/minimum threshold of temperature were selected to analyze the overall risk of heat and cold effects. Subgroup meta-analysis was conducted for outcomes (morbidity and mortality), definitions and thresholds of heat temperatures, and ages ( $\geq 60$ years old). Moreover, for diabetes mortality and morbidity, we conducted meta-analysis of heat temperatures grouped by different definitions and thresholds. Meta-analysis was performed separately where more than three estimates were available.

For definition 1 of heat and cold exposures, risk estimates (percent changes, RR, OR,) were converted into RR per $1^{\circ} \mathrm{C}$ change in temperature, which allowed us to quantitatively pool estimates from different studies. The standardized risk estimates are calculated by following formula (1) and (2):

$$
\begin{aligned}
& \text { Percent Changes }=(R R-1) \times 100 \% \\
& R R_{(\text {Standardised })}=R R_{(\text {Original })}^{\text {Increment }_{(\text {Standardised })} / \text { Increment }_{(\text {Original })}}
\end{aligned}
$$

One study (Li et al. 2014a) did not show the overall estimate, which reported the stratified estimate of analyzed cities independently. Therefore, we pooled the stratified estimates (Harbin, Nanjing, Shenzhen and Chongqing in China) of this study in meta-analysis. In addition, the locations and time of two studies (Ostro et al. 2010 and Li et al. 2014b) were overlapped with the other two studies (Sherbakov et al. 2018 and Li et al. $2014 \mathrm{a}$ ), therefore, we only included the study of Sherbakov et al. 2018 and Li et al. 2014a in the systematic review and meta-analysis.

\subsection{Sensitivity analyses}

Sensitivity analyses were performed to examine the robustness of our outcomes by excluding studies in which the location and study time were partially overlapping from the included studies.

\subsection{Statistical analysis}

Random-effects model was performed. Heterogeneity between included studies was assessed by the Chi-square test and the extent of inconsistency was evaluated by the $\mathrm{I}^{2}$. $\mathrm{p}<0.05$ was considered statistically significant. All analyses were conducted using Stata software (16.0).

\subsection{Risk of bias assessment}

We used a domain-based risk of bias (RoB) assessment tool (World Health Organization 2020) developed by the WHO Global Air Quality Guidelines Working Group on Risk of Bias Assessment to assess the risk of bias on all included articles. There were six domains (confounding, selection bias, exposure assessment, outcome measurement, missing data, and selective reporting) and each domain had 1 to 4 subdomains respectively in the RoB assessment tool. The instrument was designed specifically to assess risk of bias of air pollution studies included in systematic reviews, of studies on short- and long-term exposure to air pollutants (World Health Organization 2020). However, we focused on extreme temperatures rather than the health effects of pollutants on diabetes, so we replaced the key confounding factor temperature in the confounding domain of RoB assessment tool with 
pollutants. According to the criteria of RoB assessment tool, each subdomain got a 'low', 'moderate' or 'high' judgment of bias risk. To make an overall judgment on a domain, the following approach was adopted: if any subdomain has a high risk of bias, the whole domain will be regarded as a high risk of bias; if all subdomains have a low risk of bias, the whole domain will be rated as low risk of bias; when at least one subdomain has a moderate risk of bias, and other subdomains have no high risk of bias, the whole domain will be rated as moderate risk of bias. All of the included studies were evaluated independently by two reviewers (Xinyi Wang \& Liangzhen Jiang), and resolved by a third reviewers (Xuping Song) in case of disagreement.

\section{Result}

A total of 2104 articles were identified. After excluded duplicated articles, 974 records were excluded based on title or abstract, with 63 studies for full-text review. Ultimately, 32 studies accorded with our criteria. 18 of the 32 included studies were combined in the meta-analysis (Fig. 1).

\subsection{Study characteristics}

The detailed information of the included studies was presented in Table 1. Among the eligible studies, 11 studies were conducted in USA, 7 in China, 4 in Australia, 2 in Italy, 2 in Thailand, and the other 7 studies distributed in Spain, Sweden, South Korea, Brazil, UK, Philippine and Canada (Åström et al conducted their study in Italy and Sweden). These 32 studies, 20 used time series design and 12 used case-crossover design. Of the included studies, 17 reported the effects of heat effect only, 5 reported heat waves only, 2 reported both heat effect and heat waves, 8 reported both heat and cold effect. For exposure variable, 22 studies used temperature with one study (Ostro et al. 2010) used both air temperature and apparent temperature, 5 used apparent temperature, and 2 used humidex. For outcomes, 18 studies explored the effects of extreme temperatures on diabetes mortality, 16 studies evaluated morbidity, with two studies (Liu et al. 2018 and Wilson et al. 2013) explored both mortality and morbidity. For definition of heat/cold exposures, 13 studies adopted temperature exposure definition 1, 10 used definition 2, and 5 studies applied definition 3.

\subsection{Overall analysis of extreme temperatures on diabetes}

There were 18 studies explored the impact of heat exposures on diabetes, and 5 explored the impact of cold. Overall, the results of meta-analyses indicated that both heat $(\mathrm{RR}=1.032,95 \% \mathrm{Cl}: 1.021-1.044)$ and cold $(\mathrm{RR}=1.234,95 \% \mathrm{Cl}: 1.046-1.455)$ exposures have impact on diabetes (Fig. 2 and Fig. 3).

There is no regionally recognized definition of heat waves so far. Generally, heat waves were defined by the duration and intensity. Due to difference of heat waves definitions, meta-analysis was not performed in our study. There were 5 studies assessed the association between heat waves and diabetes (Fig. 4). Wang et al (2012) indicated a significant association between heat waves and diabetes mortality of the elderly aged over 75 years. No significant association between heat waves and diabetes was found in other four studies (Campbell et al. 2019; Sherbakov et al. 2018; Wilson et al. 2013; Chen et al. 2017).

\subsection{Subgroup analysis}

\subsubsection{Heat temperatures of different definitions and diabetes}

Analysis of definition 1 indicated the risk of diabetes increased by $1.7 \%(95 \% \mathrm{Cl}: 0.9 \%-2.4 \%)$ per $1{ }^{\circ} \mathrm{C}$ increment exposure to heat temperatures. In addition, results of definition 2 and 3 showed that compared with the reference temperatures, heat exposures (99th) increased the risk on diabetes by 25.5\% (95\% Cl: $17.6 \%-34 \%$ ) and $11.4 \%$ (95\% Cl: 5.3\%-18\%) respectively (Figure S1).

\subsubsection{Impact of heat exposures on diabetes mortality and morbidity}

The result suggested a higher risk of heat effect for mortality on diabetes as compared to morbidity, with an increased risk of $13.9 \%$ ( $95 \% \mathrm{Cl}: 8.9 \%-19.2 \%)$ and $1.2 \%$ (95\% Cl: $0.4 \%-1.9 \%)$ respectively (Fig. 5).

Subgroup analyses were performed for the effects of heat exposures on diabetes morbidity and mortality. The results indicated that with the increase of definition 2 and definition 3 threshold (90th, 95th, 99th), the impact of heat exposures on diabetes mortality and morbidity rised (RR $=1.240,95 \%$ Cl: 1.156-1.330; RR = 1.109, 95\% Cl: 1.031-1.193) (Fig. 6 and Fig. 7).

\subsubsection{Impact of heat exposures on diabetes in different ages}

The meta-analysis result of heat effect on diabetes in different ages showed that heat exposures increased the risk on diabetes of the elderly aged 60 and over by $4 \%$ (95\% Cl: $1.7 \%-6.4 \%)$, which was higher than all populations (RR $=1.032,95 \% \mathrm{Cl}: 1.021-1.044)$ (Figure S2).

\subsection{Sensitive analysis}

Similar results were observed from the overall analysis of extreme temperatures on diabetes in the sensitive analysis. After excluding 6 studies (Vaneckova et al. 2013; Wilson et al. 2013; Li et al. 2014a; Yang et al. 2016; Ma et al. 2020; Su et al. 2020) with overlapping geographical locations and study time in the meta-analysis, the significant associations of heat $(\mathrm{RR}=1.018,95 \% \mathrm{Cl}: 1.010-1.027)$ and cold effect $(\mathrm{RR}=1.258,95 \% \mathrm{Cl}$ : $1.011-1.566)$ on diabetes were still robust (Figure S3 and Figure S4).

\subsection{Risk of bias}

The risk of bias rating for the included studies was shown in Table 2 and more analytically in Table S2. In general, most of the included studies were rated as "low" risk in domains such as selection bias, outcome measurement, missing data and selective reporting. In the confounding domain, only 5 studies (Stafoggia et al. 2006; Bai et al. 2016; Pudpong and Hajat 2011; Wang et al. 2014; Wilson et al. 2013) were evaluated for “low" risk, 13 were 
"moderate" risk, with 14 studies were evaluated for "high" risk, for the reason that not all of the key potential confounders (e.g. pollutant and influenza) were adjusted in the analysis. 14 studies were judged as "moderate" risk in exposure assessment domain, because exposure data were obtained from only one monitoring site over a large geographic area. 4 studies were evaluated for "moderate" risk in selection bias, as the result of the study populations only included age-specific people like the elderly or urban residents but not rural residents.

\section{Discussion}

In this systematic review, we evaluated the published articles on the relationship between extreme temperatures and diabetes. 6 electronic databases were searched comprehensively. Finally, 32 articles were included and 18 were pooled in meta-analysis. We found that both heat and cold temperatures had significant impacts on diabetes, and the impact of heat exposures on diabetes mortality was higher than morbidity. We also found that the higher the threshold for heat temperatures, the greater the impact on diabetes mortality and morbidity. Besides, a higher percentage of the elderly aged 60 years and over with diabetes due to high temperatures compared to the general populations were found. The sensitivity analysis results were consistent with the overall analysis; hence the results were reliable in this study.

\subsection{Extreme temperatures and diabetes}

We found that both heat and cold exposures have impact on diabetes. A case-only study found that patients with diabetes had a higher risk of dying on hot days than other subjects (Schwartz 2005). Previous studies suggested a complex association. While there were some studies support our results (Lavigne et al. 2014; Lu et al. 2016; Lam et al. 2018; Hajat et al. 2017; Schwartz 2005), Ogbomo et al, Kim et al and Gasparrini et al found no relationship between heat exposures and diabetes, Su et al and Wang et al (2014) found a significant association between heat exposures and diabetes but no significant association of cold. The reason for the discrepancy may be that the study areas were located in different climate zones. In addition, the adaptability of the study populations to specific climatic zones and regional economic conditions may also contribute to the differences in results.

Diabetes is becoming a global public health problem. Global adult diabetes prevalence has risen from $4.7 \%$ in 1980 to $8.5 \%$ in 2014 (World Health Organization 2016b). The International Diabetes Federation has predicted that the prevalence of diabetes will reach 592 million cases with an additional 175 million undiagnosed by 2035 (Aguiree et al. 2013). Extreme temperatures are becoming a health threat to people with diabetes, and with global climate change especially rising temperatures, are becoming greater threat to the lives of people with diabetes. Hospitals, doctors and families should pay more attention to the effects of extreme temperatures in the care of diabetics.

\subsection{Vulnerable populations}

The elderly with diabetes aged 60 years and over showed more vulnerable to heat effect was observed in our study. Xu et al, Wilson et al and Li et al (2017) also found same results that extreme heat was associated with a greater risk of diabetes in the elderly compared to all populations or other age groups. Similarly, Lam et al found patients with diabetes aged 75 years and over were more vulnerable to heat and cold effect. Older people, already in poorer health than younger people, have a harder time adjusting in extreme heat and cold exposures with diabetes. Our finding suggests that people with diabetes, especially the elderly, should try to reduce exposures to extreme temperatures.

\subsection{Potential biological mechanisms}

The biological mechanisms of the effects of extreme temperatures on diabetes are not fully understood as yet. Potential biological mechanisms include, but are not limited to, neurological pathways, hemodynamic effects (Ely et al. 2018; Kenny et al. 2016; Vallianou et al. 2020), brown adipose tissue (Symonds et al. 2019). During heat and cold exposure, cardiovascular regulation is essential for temperature control, so blood must be redistributed to the periphery and to the core respectively to maintain a stable core temperature and thus maintain the body's thermal balance (Kenny et al. 2016). According to reports, diabetic patients have lower skin blood flow and sweat response when exposed to heat, which has a great adverse effect on cardiovascular regulation and blood sugar control. Diabetics have lower skin blood flow and significantly impaired vascular response to cold, which may make it more difficult to prevent core temperature drops associated during cold exposures. (Kenny et al. 2016). Greater degrees of neuropathy may lead to lower skin blood flow levels in diabetes patients, so that diabetics can't keep body temperature stable under heat and cold exposures. Brown adipose tissue has a unique mitochondrial protein uncoupling protein (UCP) 1 which can be activated during cold exposures, leading to increased sympathetic nervous system activity, oxidation of large amounts of lipids and glucose, and heat consumption. While with the continued rise in global temperatures, and the increased duration of "summer", the protective effect of brown adipose tissue on diabetes is limited (Symonds et al. 2019).

\subsection{Heterogeneity}

Heterogeneity may be related to study design types and statistical analysis models between studies. Secondly, regional and demographic differences may be important reason. Studies were conducted in different climate zones, the average temperature, relative humidity, air pressure and other meteorological factors are different from each other. The adaptability of residents living in different climatic zones to cold and heat temperatures is also different, and the economic level and social development between regions will have an important impact, for example, there are differences in the popularity of cooling and heating tools, such as air conditioners, between developed and developing countries. Although most studies adjusted for relative humidity and air pollutants, but there was still a part of studies did not consider the influence of atmospheric pollutants, or other important confounding factors. In addition, some studies only obtained the temperature exposures data from one monitoring site to represent the whole exposure levels of residents in a big area. Combined with the discrepancies of temperature index and lag days, all these factors leaded to the heterogeneity of the results.

\subsection{Strengths and Limitations}


This systematic review and meta-analysis provided pioneering evidence between extreme temperatures and diabetes. We analyzed the impacts of cold and heat exposures on diabetes morbidity and mortality according to different definition methods of extreme temperatures. Studies were selected in strict according to the inclusion and exclusion criteria, and the risk of bias in all included studies was assessed using the RoB quality assessment tool. In addition, sensitivity analysis was conducted to ensure the robustness of results.

Our study also has some limitations. First of all, different extreme temperatures definition methods used in the included studies limited the combination of effect sizes. Subgroup analysis on temperature definitions were performed to explore the difference effects of heat exposures on diabetes. Secondly, most of the included studies were conducted in developed and a few developing countries among temperate zone, and some used the same regional data. Sensitivity analysis on heat and cold impacts were conducted to assess the robustness of our results. Thirdly, due to the lack of data, we failed to analyze the lagged effects of extreme temperatures on health. The delayed effects of extreme temperatures on health are not clear at present, so it is necessary to study the effects of extreme temperatures on diabetes under different lagged effects.

\section{Conclusions}

Both short-term exposure to heat and cold temperatures have impact on diabetes. The elderly is the vulnerable population of diabetes exposure to heat temperatures. Developing definitions of heat waves at the regional level are suggested.

\section{Declarations}

\section{Ethics approval and consent to participate: Not applicable}

Consent for publication: Not applicable

Availability of data and materials: All data generated or analysed during this study are included in this published article and its supplementary information files.

Competing interests: None competing interests.

Funding: This study was funded by Science and Technology Program of Gansu Province (20CX4ZA027), Cost-effectiveness analysis of electrical stimulation combined with bladder function training in the treatment of neurogenic bladder with spinal cord injury (2020-RC-63) and Natural Science Foundation of Shanghai (20JR5RA262).

Authors' contributions: XS made search strategy and wrote the article; LJ analyzed data, assessed risk of bias and wrote the article; DZ wrote the article; XW searched articles and assessed risk of bias; YM and YH selected studies and extracted data, XL and JT selected studies; YM and DZ wrote the protocol and registered at the PROSPERO; WH, AS and YF checked data and results of RoB assessment; YZ made some suggestions for improvement of this article.

Acknowledgements: Funding from the Science and Technology Program of Gansu Province, Cost-effectiveness analysis of electrical stimulation combined with bladder function training in the treatment of neurogenic bladder with spinal cord injury and Natural Science Foundation of Shanghai are gratefully acknowledged.

\section{References}

Aguiree F et al. (2013) IDF Diabetes Atlas: sixth edition International Diabetes Federation

Allen et al. (2014) Climate Change 2014: Synthesis Report.

Bai L et al. (2016) Hospitalizations from Hypertensive Diseases, Diabetes, and Arrhythmia in Relation to Low and High Temperatures: Population-Based Study Scientific reports 6:30283 doi:10.1038/srep30283

Basagaña X et al. (2011) Heat waves and cause-specific mortality at all ages Epidemiology (Cambridge, Mass) 22:765-772 doi:10.1097/EDE.0b013e31823031c5

Basu R, Pearson D, Malig B, Broadwin R, Green R (2012) The effect of high ambient temperature on emergency room visits Epidemiology (Cambridge, Mass) 23:813-820 doi:10.1097/EDE.0b013e31826b7f97

Bayram H (2017) Effect of Global Climate Change-Related Factors on COPD Morbidity Tanaffos 16:S29

Bhaskaran K, Hajat S, Haines A, Herrett E, Wilkinson P, Smeeth L (2009) Effects of ambient temperature on the incidence of myocardial infarction Heart (British Cardiac Society) 95:1760-1769 doi:10.1136/hrt.2009.175000

Cai W et al. (2020) The 2020 China report of the Lancet Countdown on health and climate change The Lancet Public health doi:10.1016/s24682667(20)30256-5 
Calkins MM, Isaksen TB, Stubbs BA, Yost MG, Fenske RA (2016) Impacts of extreme heat on emergency medical service calls in King County, Washington, 2007-2012: relative risk and time series analyses of basic and advanced life support Environmental health: a global access science source 15:13 doi:10.1186/s12940-016-0109-0

Campbell SL, Remenyi TA, Williamson GJ, White CJ, Johnston FH (2019) The Value of Local Heatwave Impact Assessment: A Case-Crossover Analysis of Hospital Emergency Department Presentations in Tasmania, Australia International journal of environmental research and public health 16 doi:10.3390/ijerph16193715

Carolan-Olah M, Frankowska D (2014) High environmental temperature and preterm birth: a review of the evidence Midwifery 30:50-59 doi:10.1016/j.midw.2013.01.011

Chen T, Sarnat SE, Grundstein AJ, Winquist A, Chang HH (2017) Time-series Analysis of Heat Waves and Emergency Department Visits in Atlanta, 1993 to 2012 Environmental health perspectives 125:057009 doi:10.1289/ehp44

Costello A et al. (2009) Managing the health effects of climate change: Lancet and University College London Institute for Global Health Commission Lancet (London, England) 373:1693-1733 doi:10.1016/s0140-6736(09)60935-1

Ely BR, Clayton ZS, McCurdy CE, Pfeiffer J, Minson CT (2018) Meta-inflammation and cardiometabolic disease in obesity: Can heat therapy help? Temperature (Austin, Tex) 5:9-21 doi:10.1080/23328940.2017.1384089

Gasparrini A, Armstrong B, Kovats S, Wilkinson P (2012) The effect of high temperatures on cause-specific mortality in England and Wales Occupational and environmental medicine 69:56-61 doi:10.1136/oem.2010.059782

Green RS, Basu R, Malig B, Broadwin R, Kim JJ, Ostro B (2010) The effect of temperature on hospital admissions in nine California counties International journal of public health 55:113-121 doi:10.1007/s00038-009-0076-0

Gronlund CJ, Sullivan KP, Kefelegn Y, Cameron L, O'Neill MS (2018) Climate change and temperature extremes: A review of heat- and cold-related morbidity and mortality concerns of municipalities Maturitas 114:54-59 doi:10.1016/j.maturitas.2018.06.002

Hajat S, Haines A, Sarran C, Sharma A, Bates C, Fleming LE (2017) The effect of ambient temperature on type-2-diabetes: case-crossover analysis of 4+ million GP consultations across England Environmental health: a global access science source 16:73 doi:10.1186/s12940-017-0284-7

Hansen J, Sato M, Ruedy R (2012) Perception of climate change Proceedings of the National Academy of Sciences of the United States of America 109:14726-14727 doi:10.1073/pnas.1205276109

He Y et al. (2020) Geographical disparities in the impacts of heat on diabetes mortality and the protective role of greenness in Thailand: A nationwide case-crossover analysis The Science of the total environment 711:135098 doi:10.1016/j.scitotenv.2019.135098

Isaksen TB, Fenske RA, Hom EK, Ren Y, Lyons H, Yost MG (2016) Increased mortality associated with extreme-heat exposure in King County, Washington, 1980-2010 International journal of biometeorology 60:85-98 doi:10.1007/s00484-015-1007-9

Kenny GP, Sigal RJ, McGinn R (2016) Body temperature regulation in diabetes Temperature (Austin, Tex) 3:119-145 doi:10.1080/23328940.2015.1131506

Kim CT, Lim YH, Woodward A, Kim H (2015) Heat-attributable deaths between 1992 and 2009 in Seoul, South Korea PloS one 10:e0118577 doi:10.1371/journal.pone.0118577

Lam HCY, Chan JCN, Luk AOY, Chan EYY, Goggins WB (2018) Short-term association between ambient temperature and acute myocardial infarction hospitalizations for diabetes mellitus patients: A time series study PLoS medicine 15:e1002612 doi:10.1371/journal.pmed.1002612

Lavigne E, Gasparrini A, Wang X, Chen H, Yagouti A, Fleury MD, Cakmak S (2014) Extreme ambient temperatures and cardiorespiratory emergency room visits: assessing risk by comorbid health conditions in a time series study Environmental health: a global access science source 13:5 doi:10.1186/1476069x-13-5

Li J et al. (2017) Ambient high temperature and mortality in Jinan, China: A study of heat thresholds and vulnerable populations Environmental research 156:657-664 doi:10.1016/j.envres.2017.04.020

Li Y et al. (2014a) Association between high temperature and mortality in metropolitan areas of four cities in various climatic zones in China: a timeseries study Environmental health: a global access science source 13:65 doi:10.1186/1476-069x-13-65

Li Y et al. (2014b) Extremely cold and hot temperatures increase the risk of diabetes mortality in metropolitan areas of two Chinese cities Environmental research 134:91-97 doi:10.1016/j.envres.2014.06.022

Liu Y, Hoppe BO, Convertino M (2018) Threshold Evaluation of Emergency Risk Communication for Health Risks Related to Hazardous Ambient Temperature Risk analysis: an official publication of the Society for Risk Analysis 38:2208-2221 doi:10.1111/risa.12998 
Lu CL, Chang HH, Chen HF, Ku LE, Chang YH, Shen HN, Li CY (2016) Inverse relationship between ambient temperature and admissions for diabetic ketoacidosis and hyperglycemic hyperosmolar state: A 14-year time-series analysis Environment international 94:642-648 doi:10.1016/j.envint.2016.06.032

Ma Y, Zhou L, Chen K (2020) Burden of cause-specific mortality attributable to heat and cold: A multicity time-series study in Jiangsu Province, China Environment international 144:105994 doi:10.1016/j.envint.2020.105994

Méndez-Lázaro PA, Pérez-Cardona CM, Rodríguez E, Martínez O, Taboas M, Bocanegra A, Méndez-Tejeda R (2018) Climate change, heat, and mortality in the tropical urban area of San Juan, Puerto Rico International journal of biometeorology 62:699-707 doi:10.1007/s00484-016-1291-z

Ogbomo AS, Gronlund CJ, O'Neill MS, Konen T, Cameron L, Wahl R (2017) Vulnerability to extreme-heat-associated hospitalization in three counties in Michigan, USA, 2000-2009 International journal of biometeorology 61:833-843 doi:10.1007/s00484-016-1261-5

Ostro B, Rauch S, Green R, Malig B, Basu R (2010) The effects of temperature and use of air conditioning on hospitalizations American journal of epidemiology 172:1053-1061 doi:10.1093/aje/kwq231

Oudin Åström D, Schifano P, Asta F, Lallo A, Michelozzi P, Rocklöv J, Forsberg B (2015) The effect of heat waves on mortality in susceptible groups: a cohort study of a mediterranean and a northern European City Environmental health: a global access science source 14:30 doi:10.1186/s12940-0150012-0

Pudpong N, Hajat S (2011) High temperature effects on out-patient visits and hospital admissions in Chiang Mai, Thailand The Science of the total environment 409:5260-5267 doi:10.1016/j.scitotenv.2011.09.005

Schwartz J (2005) Who is sensitive to extremes of temperature? A case-only analysis Epidemiology (Cambridge, Mass) 16:67-72 doi:10.1097/01.ede.0000147114.25957.71

Seposo XT, Dang TN, Honda Y (2017) How Does Ambient Air Temperature Affect Diabetes Mortality in Tropical Cities? International journal of environmental research and public health 14 doi:10.3390/ijerph14040385

Sherbakov T, Malig B, Guirguis K, Gershunov A, Basu R (2018) Ambient temperature and added heat wave effects on hospitalizations in California from 1999 to 2009 Environmental research 160:83-90 doi:10.1016/j.envres.2017.08.052

Stafoggia M et al. (2006) Vulnerability to heat-related mortality: a multicity, population-based, case-crossover analysis Epidemiology (Cambridge, Mass) 17:315-323 doi:10.1097/01.ede.0000208477.36665.34

Su X, Cheng Y, Wang Y, Liu Y, Li N, Li Y, Yao X (2019) Regional Temperature-Sensitive Diseases and Attributable Fractions in China International journal of environmental research and public health 17 doi:10.3390/ijerph17010184

Symonds ME, Farhat G, Aldiss P, Pope M, Budge H (2019) Brown adipose tissue and glucose homeostasis - the link between climate change and the global rise in obesity and diabetes Adipocyte 8:46-50 doi:10.1080/21623945.2018.1551689

Vallianou NG et al. (2020) Diabetes mellitus in the era of climate change Diabetes \& metabolism doi:10.1016/j.diabet.2020.10.003

Vaneckova P, Bambrick H (2013) Cause-specific hospital admissions on hot days in Sydney, Australia PloS one 8:e55459

doi:10.1371/journal.pone.0055459

Wang XY et al. (2012) The impact of heatwaves on mortality and emergency hospital admissions from non-external causes in Brisbane, Australia Occupational and environmental medicine 69:163-169 doi:10.1136/oem.2010.062141

Wang YC, Lin YK (2014) Association between temperature and emergency room visits for cardiorespiratory diseases, metabolic syndrome-related diseases, and accidents in metropolitan Taipei PloS one 9:e99599 doi:10.1371/journal.pone.0099599

World Health Organization (2016a): WHO CALL ON COUNTRIES TO PROTECT HEALTH FROM CLIMATE CHANGE Neurosciences (Riyadh, Saudi Arabia) 21:86-87

WHO (2016b) Global report on diabetes Working Papers

World Health Organization (2020): Risk of bias assessment instrument for systematic reviews informing WHO global air quality guidelines. http://www.euro.who.int/en/health-topics/environment-and-health/air-quality/publications/2020/risk-of-bias-assessment-instrument-for-systematicreviews-informing-who-global-air-quality-guidelines-2020

Wilson LA et al. (2013) The impact of heat on mortality and morbidity in the Greater Metropolitan Sydney Region: a case crossover analysis Environmental health: a global access science source 12:98 doi:10.1186/1476-069x-12-98 
Winquist A, Grundstein A, Chang HH, Hess J, Sarnat SE (2016) Warm season temperatures and emergency department visits in Atlanta, Georgia Environmental research 147:314-323 doi:10.1016/j.envres.2016.02.022

Xu R et al. (2019) Association between Heat Exposure and Hospitalization for Diabetes in Brazil during 2000-2015: A Nationwide Case-Crossover Study Environmental health perspectives 127:117005 doi:10.1289/ehp5688

Yang J et al. (2016) The effect of ambient temperature on diabetes mortality in China: A multi-city time series study The Science of the total environment 543:75-82 doi:10.1016/j.scitotenv.2015.11.014

\section{Tables}

Table 1: 


\begin{tabular}{|c|c|c|c|c|c|c|c|c|c|}
\hline Study & Country & $\begin{array}{l}\text { Study } \\
\text { time }\end{array}$ & $\begin{array}{c}\text { Population } \\
\text { (n) }\end{array}$ & $\begin{array}{c}\text { Temperature } \\
\text { exposure }\end{array}$ & Exposure variable & $\begin{array}{l}\text { Pooled } \\
\text { ways }\end{array}$ & $\begin{array}{c}\text { Study } \\
\text { design }\end{array}$ & Outcome & Model \\
\hline $\begin{array}{l}\text { Basagaña, } \\
2011\end{array}$ & Spain & $\begin{array}{l}1983- \\
2006\end{array}$ & 11999 & Heatwave & Tmax & - & $\mathrm{CC}$ & Mortality & $\begin{array}{l}\text { Conditional } \\
\text { logistic } \\
\text { regression } \\
\text { model }\end{array}$ \\
\hline $\begin{array}{l}\text { Campbell, } \\
2019\end{array}$ & Australia & $\begin{array}{l}2008- \\
2016\end{array}$ & 1994 & Heatwave & Tmean & - & $\mathrm{CC}$ & Morbidity & $\begin{array}{l}\text { Conditional } \\
\text { multivariate } \\
\text { logistic } \\
\text { regression } \\
\text { model }\end{array}$ \\
\hline $\begin{array}{l}\text { Green, } \\
2010\end{array}$ & USA & $\begin{array}{l}1999- \\
2005\end{array}$ & 50282 & Heat & Tmean & D1 & CC & Morbidity & $\begin{array}{l}\text { Conditional } \\
\text { logistic } \\
\text { regression } \\
\text { model }\end{array}$ \\
\hline He, 2019 & Thailand & $\begin{array}{l}2000- \\
2008\end{array}$ & 59836 & Heat & Tmean & D2 & $\mathrm{CC}$ & Mortality & $\begin{array}{l}\text { Conditional } \\
\text { logistic } \\
\text { regression } \\
\text { model }\end{array}$ \\
\hline Kim, 2015 & Korea & $\begin{array}{l}1992- \\
2009\end{array}$ & 28123 & Heat & Tmax & D1 & TS & Mortality & $\begin{array}{l}\text { Generalized } \\
\text { linear } \\
\text { model }\end{array}$ \\
\hline Liu, 2018 & USA & $\begin{array}{l}1998- \\
2014\end{array}$ & 603447 & Heat/cold & $\underset{\text { index }}{\text { Maximum heat }}$ & D2 & TS & Mortality/Morbidity & $\begin{array}{c}\text { Generalized } \\
\text { linear } \\
\text { model }\end{array}$ \\
\hline $\begin{array}{l}\text { Méndez- } \\
\text { Lázaro, } \\
2016\end{array}$ & USA & $\begin{array}{l}2009- \\
2013\end{array}$ & 460 & Heat & Tmax/Tmean/Tmin & D3 & TS & Mortality & $\begin{array}{l}\text { Poisson } \\
\text { regression } \\
\text { model }\end{array}$ \\
\hline $\begin{array}{l}\text { Ostro, } \\
2010\end{array}$ & USA & $\begin{array}{l}1999- \\
2005\end{array}$ & 98476 & Heat & AT/Tmax/Tmin & D1 & $\mathrm{CC}$ & Morbidity & $\begin{array}{l}\text { Conditional } \\
\text { logistic } \\
\text { regression } \\
\text { model }\end{array}$ \\
\hline $\mathrm{Xu}, 2019$ & Brazil & $\begin{array}{l}2000- \\
2015\end{array}$ & 553351 & Heat & Tmean & D1 & $\mathrm{CC}$ & Morbidity & $\begin{array}{l}\text { Logistic } \\
\text { regression } \\
\text { model }\end{array}$ \\
\hline $\begin{array}{l}\text { Stafoggia, } \\
2006\end{array}$ & Italy & $\begin{array}{l}1997- \\
2003\end{array}$ & 20297 & Heat & AT & D2 & $\mathrm{CC}$ & Mortality & $\begin{array}{c}\text { Conditional } \\
\text { logistic } \\
\text { regression } \\
\text { model }\end{array}$ \\
\hline Bai, 2016 & Canada & $\begin{array}{l}1996- \\
2013\end{array}$ & 324034 & Heat/cold & Tmean & D2 & TS & Morbidity & $\begin{array}{l}\text { Distributed } \\
\text { lag non- } \\
\text { linear } \\
\text { model }\end{array}$ \\
\hline $\begin{array}{l}\text { Basu, } \\
2012\end{array}$ & USA & $\begin{array}{l}2005- \\
2008\end{array}$ & 80769 & Heat & AT & D1 & $\mathrm{CC}$ & Morbidity & $\begin{array}{l}\text { Conditional } \\
\text { logistic } \\
\text { regression } \\
\text { model }\end{array}$ \\
\hline $\begin{array}{l}\text { Calkins, } \\
2016\end{array}$ & USA & $\begin{array}{l}2007- \\
2012\end{array}$ & 10916 & Heat & Maximum humidex & D3 & TS & Morbidity & $\begin{array}{l}\text { Poisson } \\
\text { regression } \\
\text { model }\end{array}$ \\
\hline $\begin{array}{c}\text { Gasparrini, } \\
2015\end{array}$ & UK & $\begin{array}{l}1993- \\
2006\end{array}$ & 25554 & Heat & Tmax & D1 & TS & Mortality & $\begin{array}{c}\text { Non-linear } \\
\text { model }\end{array}$ \\
\hline $\begin{array}{l}\text { Isaksen, } \\
2015\end{array}$ & USA & $\begin{array}{l}1980- \\
2010\end{array}$ & NR & Heat & Maximum humidex & D3/D1 & TS & Mortality & $\begin{array}{l}\text { Poisson } \\
\text { regression } \\
\text { model }\end{array}$ \\
\hline Li, 2017 & China & $\begin{array}{l}2007- \\
2013\end{array}$ & 2813 & Heat & Tmax/Tmin/Tmean & D1 & TS & Mortality & $\begin{array}{l}\text { Generalised } \\
\text { additive } \\
\text { model }\end{array}$ \\
\hline $\mathrm{Li}, 2014 \mathrm{~b}$ & China & $\begin{array}{l}2008- \\
2012\end{array}$ & 3472 & Heat/cold & Tmax/Tmin/Tmean & D1 & TS & Mortality & $\begin{array}{c}\text { Distributed } \\
\text { lag non- } \\
\text { linear } \\
\text { model }\end{array}$ \\
\hline Li, 2014a & China & $\begin{array}{l}2004- \\
2012\end{array}$ & 4949 & Heat & Tmax/Tmin/Tmean & D1 & TS & Mortality & $\begin{array}{c}\text { Generalized } \\
\text { additive } \\
\text { model }\end{array}$ \\
\hline Ogbomo, & USA & $\begin{array}{l}2000- \\
2009\end{array}$ & 26363 & Heat & Tmean & D3 & $\mathrm{CC}$ & Morbidity & $\begin{array}{l}\text { Conditional } \\
\text { logistic } \\
\text { regression } \\
\text { model }\end{array}$ \\
\hline $\begin{array}{l}\text { Åström, } \\
2015\end{array}$ & Italy/Sweden & $\begin{array}{l}2000- \\
2008\end{array}$ & 66188 & Heatwave & AT & - & TS & Mortality & $\begin{array}{l}\text { Generalized } \\
\text { additive } \\
\text { model }\end{array}$ \\
\hline $\begin{array}{l}\text { Pudpong } \\
\text { and Hajat, } \\
2011\end{array}$ & Thailand & $\begin{array}{l}2002- \\
2006\end{array}$ & 46169 & Heat & Tmean & D1 & TS & Morbidity & $\begin{array}{c}\text { Generalized } \\
\text { negative } \\
\text { binomial } \\
\text { regression } \\
\text { model }\end{array}$ \\
\hline $\begin{array}{l}\text { Seposo, } \\
2017\end{array}$ & Philippines & $\begin{array}{l}2006- \\
2011\end{array}$ & 16980 & Heat/cold & Tmean & D2 & TS & Mortality & $\begin{array}{c}\text { Distributed } \\
\text { lag non- } \\
\text { linear } \\
\text { model }\end{array}$ \\
\hline $\begin{array}{c}\text { Sherbakov, } \\
2018\end{array}$ & USA & $\begin{array}{l}1999- \\
2009\end{array}$ & 230993 & Heat/heatwave & Tmean & D1 & TS & Morbidity & $\begin{array}{c}\text { Distributed } \\
\text { lag non- } \\
\text { linear } \\
\text { model }\end{array}$ \\
\hline $\begin{array}{l}\text { Chen, } \\
2017\end{array}$ & USA & $\begin{array}{l}1993- \\
2012\end{array}$ & 70076 & Heatwave & Tmax/Tmin/Tmean & - & TS & Morbidity & $\begin{array}{l}\text { Poisson log- } \\
\text { linear } \\
\text { model }\end{array}$ \\
\hline $\begin{array}{c}\text { Vaneckova, } \\
2013\end{array}$ & Australia & $\begin{array}{l}1991- \\
2009\end{array}$ & 97418 & Heat & Tmean & D3 & $\mathrm{CC}$ & Morbidity & $\begin{array}{c}\text { Conditional } \\
\text { logistic }\end{array}$ \\
\hline
\end{tabular}




\begin{tabular}{|c|c|c|c|c|c|c|c|c|c|}
\hline $\begin{array}{l}\text { Wang, } \\
2012\end{array}$ & Australia & $\begin{array}{l}1996- \\
2005\end{array}$ & 16602 & Heatwave & Tmax & - & $\mathrm{CC}$ & Mortality & $\begin{array}{l}\text { Conditional } \\
\text { logistic } \\
\text { regression } \\
\text { model }\end{array}$ \\
\hline $\begin{array}{l}\text { Wang, } \\
2014\end{array}$ & China & $\begin{array}{l}2000- \\
2009\end{array}$ & 3573 & Heat/cold & Tmean & D2 & TS & Morbidity & $\begin{array}{c}\text { Distributed } \\
\text { lag non- } \\
\text { linear } \\
\text { model }\end{array}$ \\
\hline $\begin{array}{l}\text { Wilson, } \\
2013\end{array}$ & Australia & $\begin{array}{l}1997- \\
2010\end{array}$ & NR & Heat/heatwave & Tmax & D2 & $\mathrm{CC}$ & Morbidity/Mortality & $\begin{array}{l}\text { Conditional } \\
\text { logistic } \\
\text { regression } \\
\text { model }\end{array}$ \\
\hline $\begin{array}{l}\text { Winquist, } \\
2016\end{array}$ & USA & $\begin{array}{l}1993- \\
2012\end{array}$ & 70076 & Heat & Tmax & D1 & TS & Morbidity & $\begin{array}{c}\text { Generalized } \\
\text { linear } \\
\text { model }\end{array}$ \\
\hline $\begin{array}{l}\text { Yang, } \\
2016\end{array}$ & China & $\begin{array}{l}2007- \\
2013\end{array}$ & 76710 & Heat/cold & Tmean & D2 & TS & Mortality & $\begin{array}{c}\text { Distributed } \\
\text { lag non- } \\
\text { linear } \\
\text { model }\end{array}$ \\
\hline Ma, 2020 & China & $\begin{array}{l}2014- \\
2017\end{array}$ & 49237 & Heat/cold & Tmean & D2 & TS & Mortality & $\begin{array}{c}\text { Distributed } \\
\text { lag non- } \\
\text { linear } \\
\text { model }\end{array}$ \\
\hline Su, 2020 & China & $\begin{array}{l}2014- \\
2017\end{array}$ & 34361 & Heat/cold & Tmean & D2 & TS & Mortality & $\begin{array}{c}\text { Distributed } \\
\text { lag } \\
\text { nonlinear } \\
\text { model }\end{array}$ \\
\hline
\end{tabular}

NR: Not reported; Tmax/Tmean/Tmin/AT: Maximum temperature/Mean temperature/Minimum temperature/Apparent temperature; D1/D2/D3: Definition 1/2/3; TS: Time series; CC: Case crossover

Table 2:

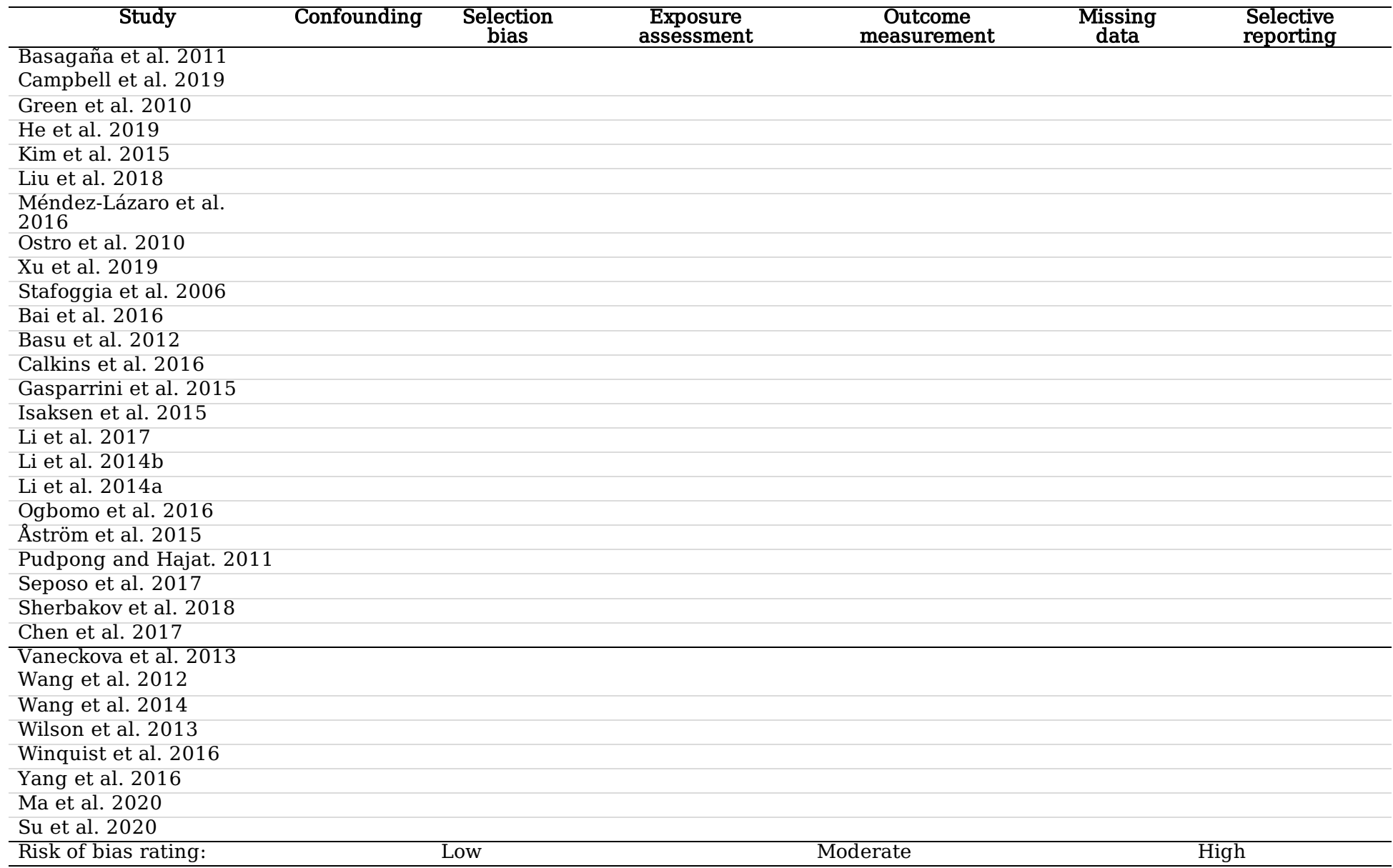




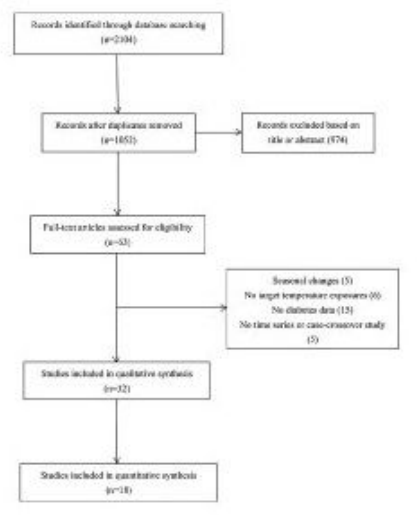

Figure 1

flowchart

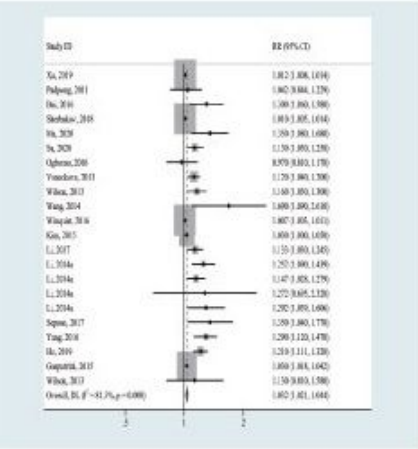

Figure 2

Overall analysis of extreme temperatures on diabetes

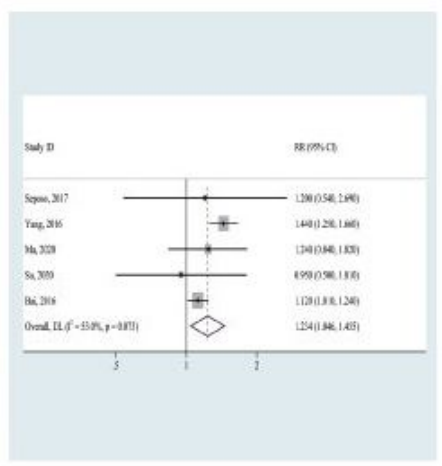

Figure 3

Overall analysis of extreme temperatures on diabetes 


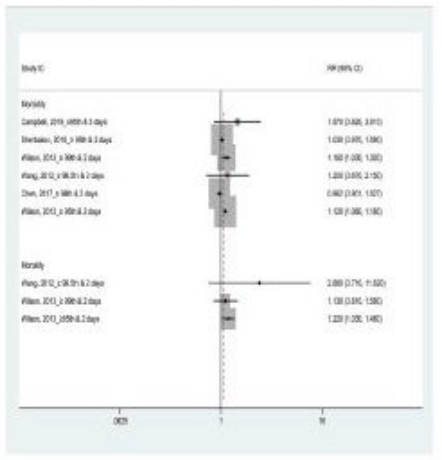

\section{Figure 4}

Overall analysis of extreme temperatures on diabetes

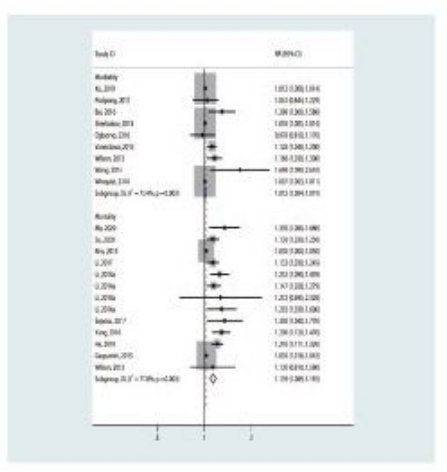

Figure 5

Impact of heat exposures on diabetes mortality and morbidity

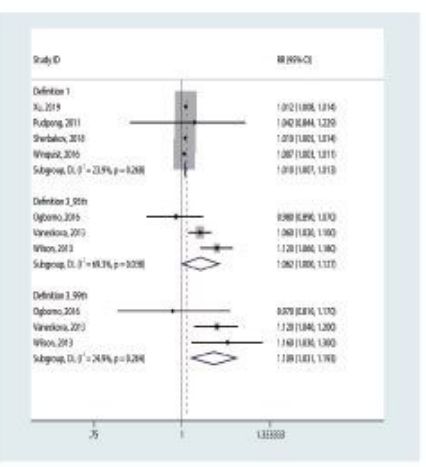

Figure 6

Impact of heat exposures on diabetes mortality and morbidity

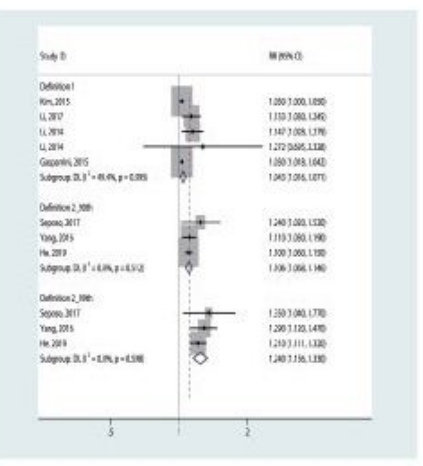

Figure 7 
Impact of heat exposures on diabetes mortality and morbidity

\section{Supplementary Files}

This is a list of supplementary files associated with this preprint. Click to download.

- Figures1.eps

- Figures2.eps

- Figures3.eps

- Figures4.eps

- Tables1.docx

- Tables2.xIsx 